\title{
Development of a novel Dual-Order protein-based Nanodelivery carrier that rapidly Targets Low-Grade Gliomas with Microscopic Metastasis in vivo
}

Zihao Wang $\dagger$, Xinbo Zhou $\dagger$, Yuru Xu†, Shiyong Fan $\dagger$, Ning Tian $\S$, Wenyuan

Zhang $\$$, Fugeng Sheng $\S *$ Jian Lin $\$ *$, Wu Zhong †*

* Corresponding authors

$\uparrow$ Beijing Institute of Pharmacology and Toxicology, No. 27 Taiping Road,

Beijing ,100850, China

\$Synthetic and Functional Biomolecules Center, College of Chemistry and Molecular Engineering, Peking University, Beijing, 100871,China

$\S$ Chinese People's Liberation Army Hospital 307, 8 East st, Fengtai District, Beijing, 100071,China

*E-mail: zhongwu@bmi.ac.cn*E-mail: linjian@pku.edu.cn

*E-mail:fugeng_sheng@163.com

Supporting Information

Experimental Section

\section{Characterization}

Transmission electron microscopy (TEM) images were obtained from an HITACHI-H-7650microscope.Dynamic light scattering (DLS) was measured using a 
particle size analyzer (Zetasizer Nano ZS-90, Malvern,England). The concentrations of Gd was quantified using an inductively coupled plasma-mass spectrum (ICP-MS, 7500ce, Agilent, USA).UV-Vis-NIR absorption spectra were measured on UV-Vis spectrophotometer(UV-2550, SHIMADZU, Japan).

\section{Cell culture}

Human glioma cancer U87MG cells and human normal HEK293T cells were obtained from American type culture collection (ATCC) and cultured at $37{ }^{\circ} \mathrm{C}$ under 5 $\% \mathrm{CO}_{2}$. All cells culture related eagents were purchased from Invitrogen. The base medium for HEK293T cell line is Dulbecco's Modified Eagle's Medium (DMEM). To make the complete growth medium, add the following components to the base medium: 10\% FBS, $2 \mathrm{mM}$ L-gliyamine, 1\% penicillin /Streptomycin. The base medium for U87MG cell line is Eagle's Minimum Essential Medium(EMEM). To make the complete growth medium, add the $10 \%$ FBS.

\section{Design, expression, purifying and characterization of Fn-Rev-Ang}

Mutagenesis of Rev-Ang-His proteins conjugated Ferritin (Fn-Rev-Ang). The $\mathrm{N}$-terminal of the Ferritin is exposed on the ferritin nanocage. The Rev-Ang-His protein was incorporated at the N-terminal of the ferritin. The Fn-Rev-Ang protein was expressed in E.Coli. Cultures of 1L each of E.Coli (BL21) containing pET-28a (+) Fn-Rev-Ang plasmid were grown 8h in Ampicillin. E.Coli was induced by IPTG $(1.0 \mathrm{mM})$ which incubated overnight in $16^{\circ} \mathrm{C}$. E. Coli were collected by centrifugation. After sonication on ice and centrifuged solution, the supernatant were purifying by both NTA-Ni column and size exclusion chromatography. We can both get purified Fn-Rev-Ang with two kinds of methods.

\section{Doxorubicin and GdDTPA encapsulation in Fn-Rev-Ang nanocage}

Fn-Rev-Ang at $2 \mathrm{mg} / \mathrm{mL}$ was dissolved in PBS (pH 7.4). Fn-Rev-Ang solution was incubated at $\mathrm{pH} 2.5$ by adding $\mathrm{HCl}(1.0 \mathrm{M})$ for $5 \mathrm{~min}$. Doxorubicin hydrochloride or GdDTPA was added to solution at 500:1 molar ratio. The $\mathrm{pH}$ was then increased to 8.0 with $\mathrm{NaOH}(1.0 \mathrm{M})$. The solution was stirred at room temperature for $2 \mathrm{~h}$. Dialyzed and PBS at pH7.4 to remove carried Doxorubicin or GdDTPA. Centrifuged at $12000 \mathrm{rpm}$ for $10 \mathrm{~min}$ at $4{ }^{\circ} \mathrm{C}$. Supernatant was concentrated and stored at $4{ }^{\circ} \mathrm{C}$ 
Supernatant was conventrated. The Doxorubicin concentration was determined by absorbance at $485 \mathrm{~nm}$, the GdDTPA concentration was determined by inductively coupled plasma-MS (ICP-MS) and the concentration of Fn-Rev-Ang was determined by nanodrop. The ratio of Doxorubicin: Fn-Rev-Ang was calculated to be 36:1 and GdDTPA : Fn-Rev-Ang was 227:1.

\section{Confocal Fluorescence Microscopic Imaging}

U87MG (ATCC) and HEK293T (ATCC) were cultured as recommended. Fluorescence microscopic images was collected by Leica (Leica, German) confocal laser scanning microscopic by using 63x oil immersion lens. Hoechst 33342 was excited with $360 \mathrm{~nm}$ and emission was detected at $480 \mathrm{~nm}$.Cy5.5 was excited with $660 \mathrm{~nm}$ and emission was detected at 710nm.Doxorubincin was excited with 470nm and emission was detected at $590 \mathrm{~nm}$.Lysotracker was excited with 440nm and emission was detected at $510 \mathrm{~nm} . \mathrm{U} 87 \mathrm{MG}$ and HEK293T were treated with $0.1 \mu \mathrm{M}$, $0.2 \mu \mathrm{M}, 0.4 \mu \mathrm{M}$ by incubated by Fn-Rev-Ang-Dox-Cy5.5 for $2 \mathrm{~h}$. At the end of incubation, the cells were washed and imaged.

\section{In vitro MRI study}

Standard spin-echo sequence on a 3.0 T MR scanner (SIEMRNS AG, Germany) at room temperature was used for measuring the relaxation time $\mathrm{T} 1$. Fn-Rev-Ang-GdDTPA solutions with different concentrations of Gd (0 - $1.0 \mathrm{mM})$ were dispersed in PBS. After acquiring T1-weighted MR images, the signal intensity was measured with selected region of interests for each sample. Relaxation rates $\mathrm{r} 1$ $(1 / \mathrm{T} 1)$ were measured from the relaxation time (T1) at various Gd concentrations. T1-mapping image sequence is $\mathrm{TR}=500 \mathrm{~ms}, \mathrm{TE}=36.8 \mathrm{~ms}, \mathrm{FOV}=180 \times 180 \mathrm{~mm}^{2}$, slice $=5$, slice thickness $=3 \mathrm{~mm}$, matrix size $=300 \times 300$.

\section{In vivo MRI study}

U87MG cells $\left(5 \times 10^{5}\right)$ were inoculated into the right cauolate by using a stereotactic fixation device. The xenograft tumor with diameter of $1.0 \mathrm{~mm}$ can be used for MR imaging after inoculation for 10 days. The mice with $15 \mathrm{~g}$ body weight were anesthetized with chloral hydrate $(7 \%)$ by intraperitoneal injection during the scans.T1 MRI ( time of restoration (TR) set as $500 \mathrm{~ms}$, the time of echo (TE) as 11 
$\mathrm{ms}$, the flip angles as $150^{\circ}$, and the thickness as $0.8 \mathrm{~mm}, 3.0 \mathrm{~T}^{\circ}$ SIEMENS) was used to observe the contrast enhancement generated every $2 \mathrm{~min}$ after ICV injection of Fn-Rev-Ang-GdDTPA, Fn-GdDTPA, GdDTPA (0.01 mM/kg Gd equivalents ). To characterize the changes in signal intensity within the tumor tissues and other normal brain tissues, region of interest (ROI) analysis was performed on the T1 MR images. ROI analysis by SIEMENS software (Multimodality Workplace).

\section{In vivo therapy study}

In order to evaluate the therapeutic effects of Fn-Rev-Ang-Dox in U87MG tumor models and compare with the same dose of clinically approved free Doxorubicin, Fn-Rev-Ang-Dox (10 mg/kg Dox equivalents), and PBS and free Dox was injected i.v. every 2 days into tumor-bearing mice after inoculation for 10 days. With U87MG (express luciferin gene) -bearing mice models used, we can evaluate gliomas volume by tumors bioluminescence intensities. The tumors bioluminescence intensities in PBS-treated groups grew rapidly, spinal cord metastatic tumors signals were found. Free dox-treated groups tumors signals remain unchanged. Fn-Rev-Ang-Dox treated groups resulted in visible regression of tumor growth, which correlated well with increase in animal survival. 
1.The statistical histogram of the Fn-Rev-Ang / Fn particle size in different $\mathrm{pH}$ solution.Large size can promote the long-term retention and enrichment of nanoparticles in the tumor site, and improve the enrichment of drugs in the tumor site.

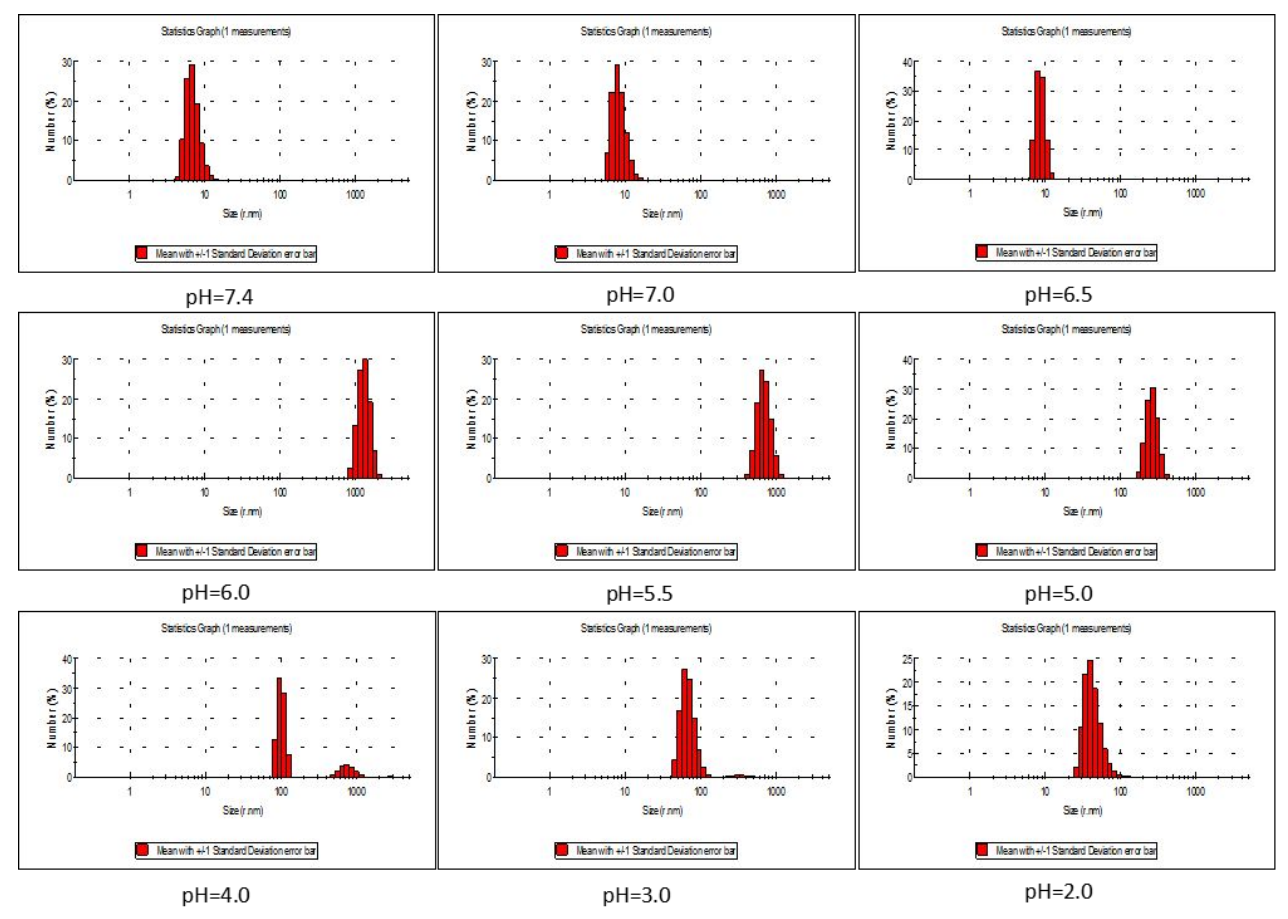

Figure S1.The statistical histogram of the Fn-Rev-Ang particle size in different pH solution

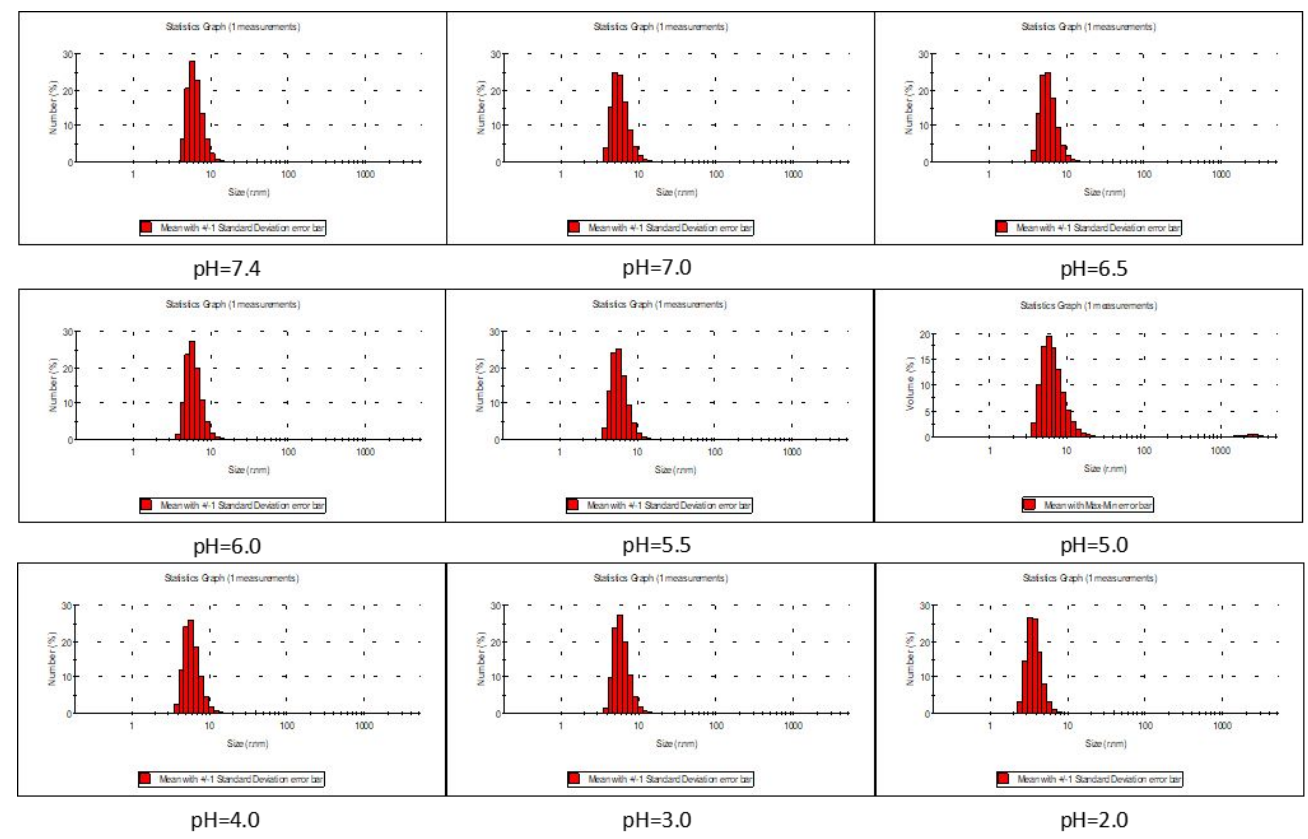


Figure S2. The statistical histogram of the Fn particle size in different $\mathrm{pH}$ solution

2. Fluorescence imaging in vivo. Mice were injected i.v. with free Cy5.5/Fn-Rev-Ang-Cy5.5 and imaged every 3 min for 45 minutes

2.The fluorescence imaging results of free Cy5.5 and Fn-Rev-Ang-Cy5.5 (pseudo-color) are shown as Figure S3.
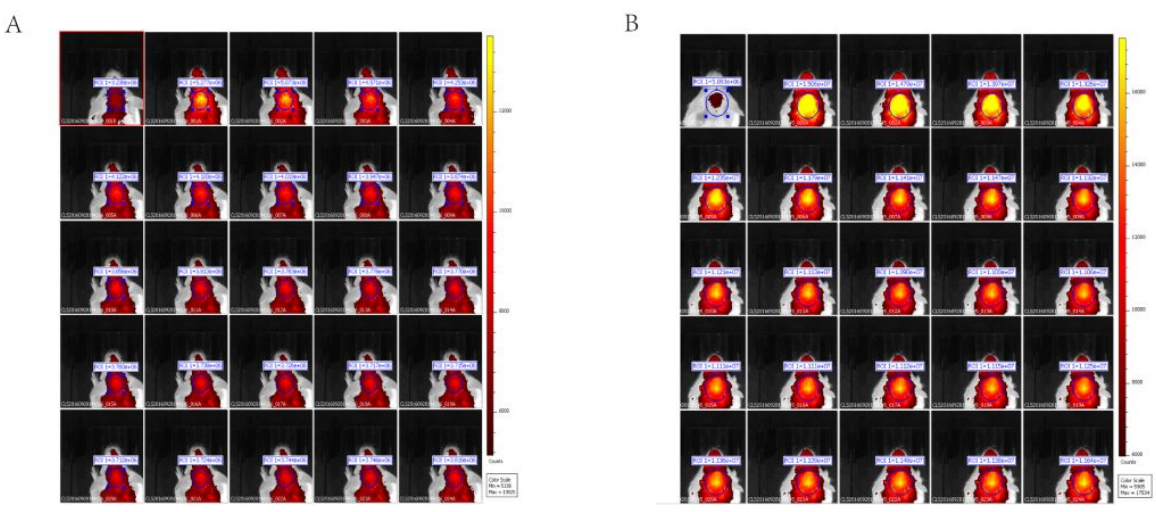

Figure S3 (A) The mice in the left group were imaged every 3 minutes after free Cy5.5 was injected into the tail vein. (B) The mice in the right group were imaged every 3 minutes after Fn-Rev-Ang-Cy5.5 was injected into the tail vein. 
3.Biodistribution data for Fn-Rev-Ang-Cy5.5 nude mice, showing all collected organs. 
A

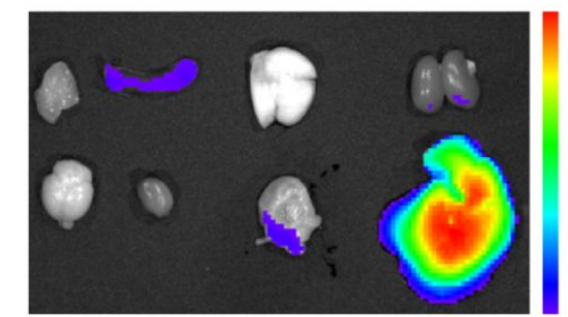

$\mathrm{C}$

$\mathrm{D}$

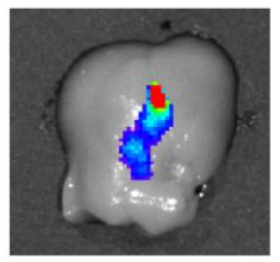

B

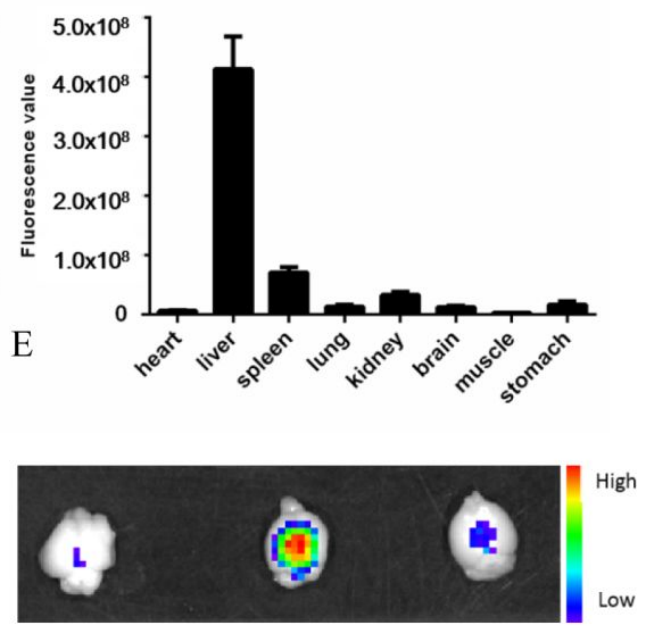

Figure S4. Distribution of whole body organs in mice after injection of Fn-Rev-Ang-Cy5.5.(A) Organ distribution after injection (first row from left to right: muscle, spleen, lung, kidney; 2nd row from left to right: brain, heart, stomach, liver) (B) The statistical distribution of fluorescence of various organs(C) (D) Gallbladder imaging in fluorescence and MRI (E) Brains fluorescence imaging of Cy5.5-PBS (left), Fn-Rev-Ang-Cy5.5 (middle), Fn-Cy5.5 (right) 
4. Transfer efficiency of Fn-Rev-Ang into U87MG cells within 40min and distribution of organelles in Fn-Rev-Ang-transferred cells within 24h

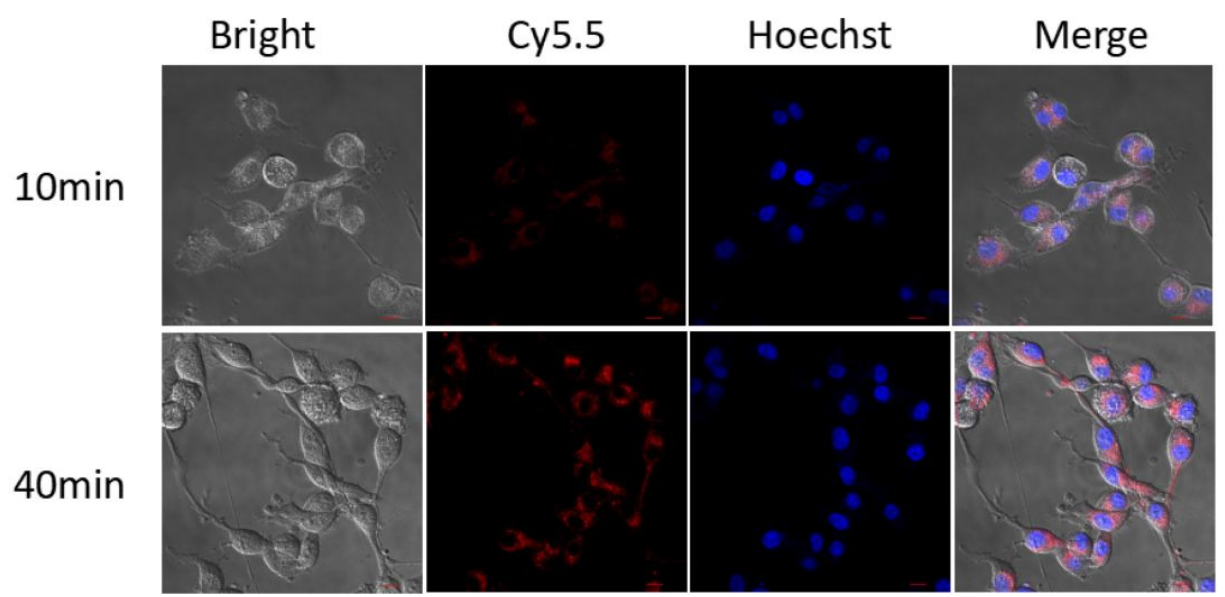

Figure S5 Transfer efficiency of Fn-Rev-Ang into U87MG cells within 40min 


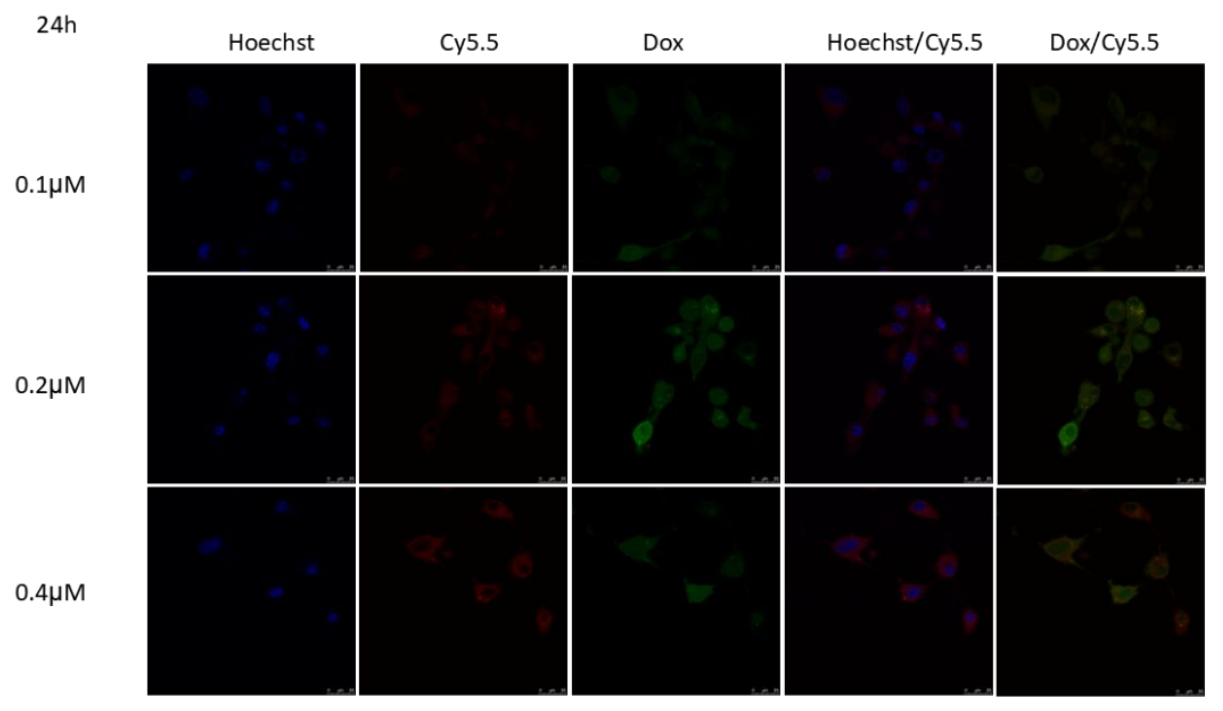

Figure S6 Distribution of organelles in Fn-Rev-Ang-Dox transferred U87MG cells within $24 \mathrm{~h}$.

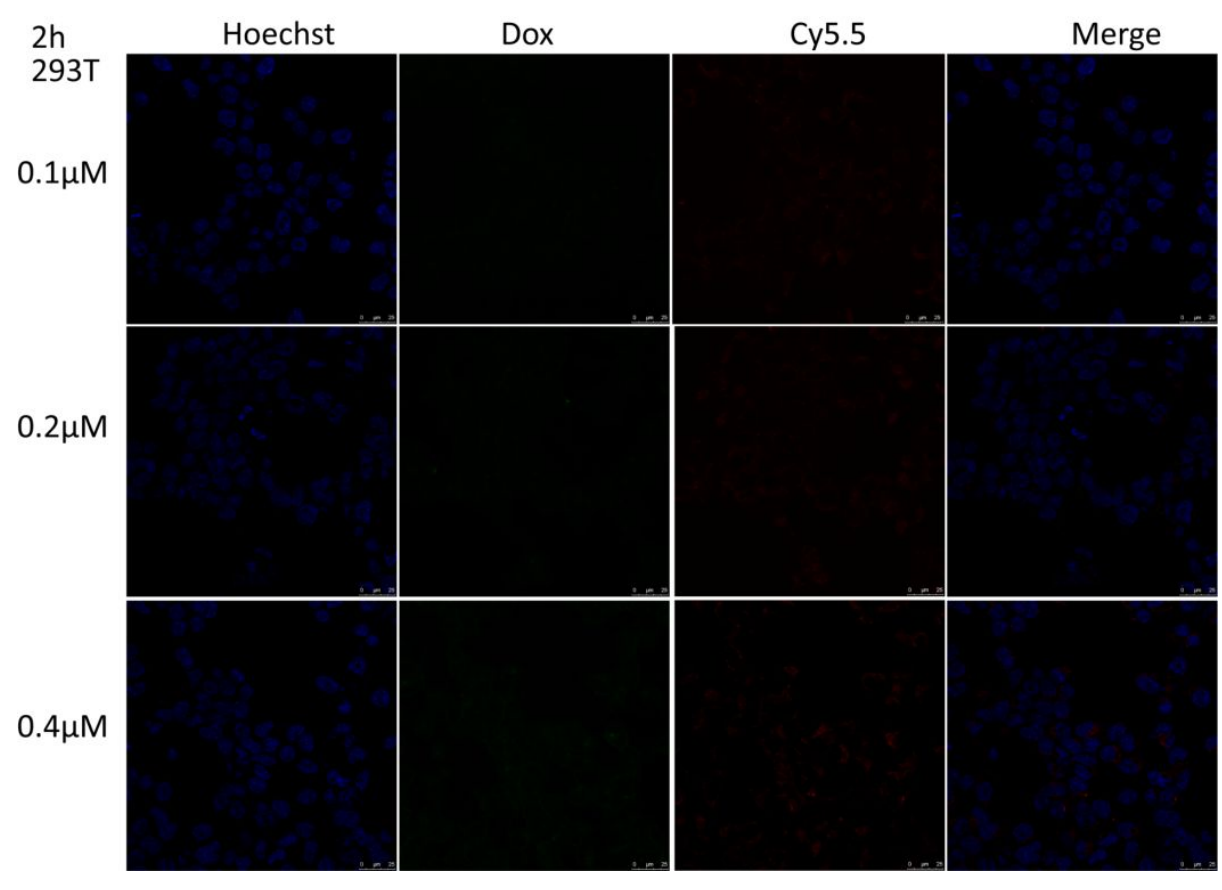

Figure S7 Distribution of organelles in Fn-Rev-Ang-Dox transferred HEK-293T cells within $24 \mathrm{~h}$. 
5. Schematic diagram of tumor inoculation and distribtion of Gd elements in each hemisphere of the brain 


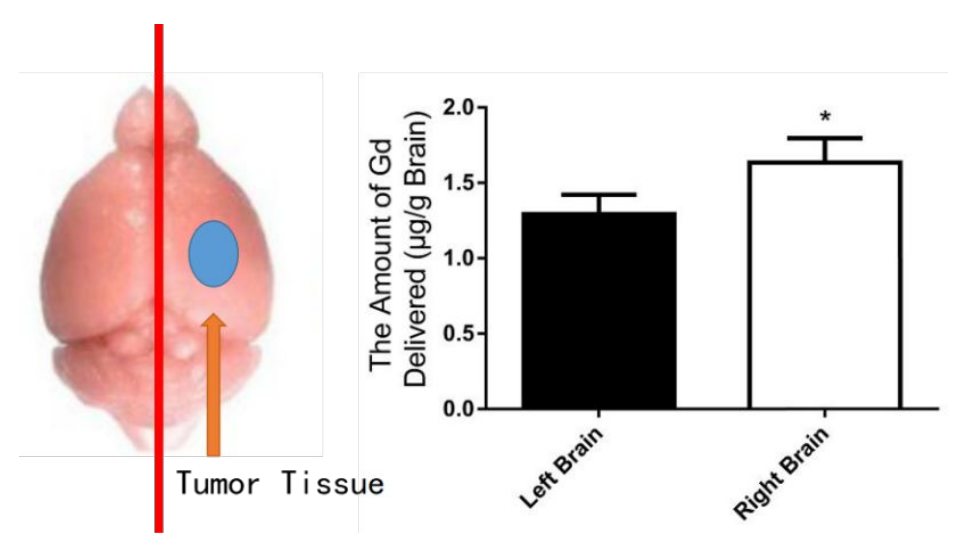

FigureS8 Schematic diagram of tumor innoculation and distribtion of Gd elements in left and right hemisphere of the brain after injected Fn-Rev-Ang-GdDTPA for $40 \mathrm{~min}$ 
6. MRI of organs distribution, including bladder, brain, tumor and muscle.

A

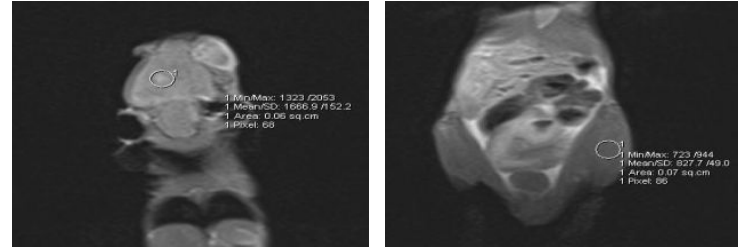

B

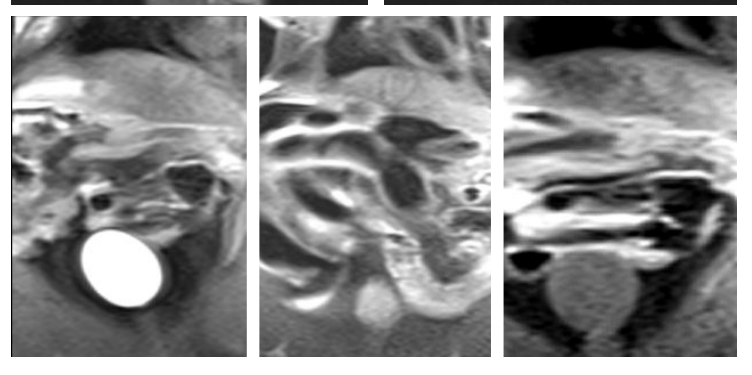

C

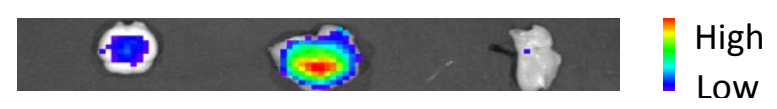


FigureS9 (A) MRI of organs distribution, including tumor(left) and muscle(right) (B) Bladder MR imaging after injected GdDTPA, Fn-GdDTPA, Fn-Rev-Ang-GdDTPA(from left to right) (C) Fluorescence imaging for brain(left), subcutaneous tumor (middle) and muscle (right) after injected Fn-Rev-Ang-Cy5.5.

7. HE staining of organs from Fn-Rev-Ang-GdDTPA-injecting mice 


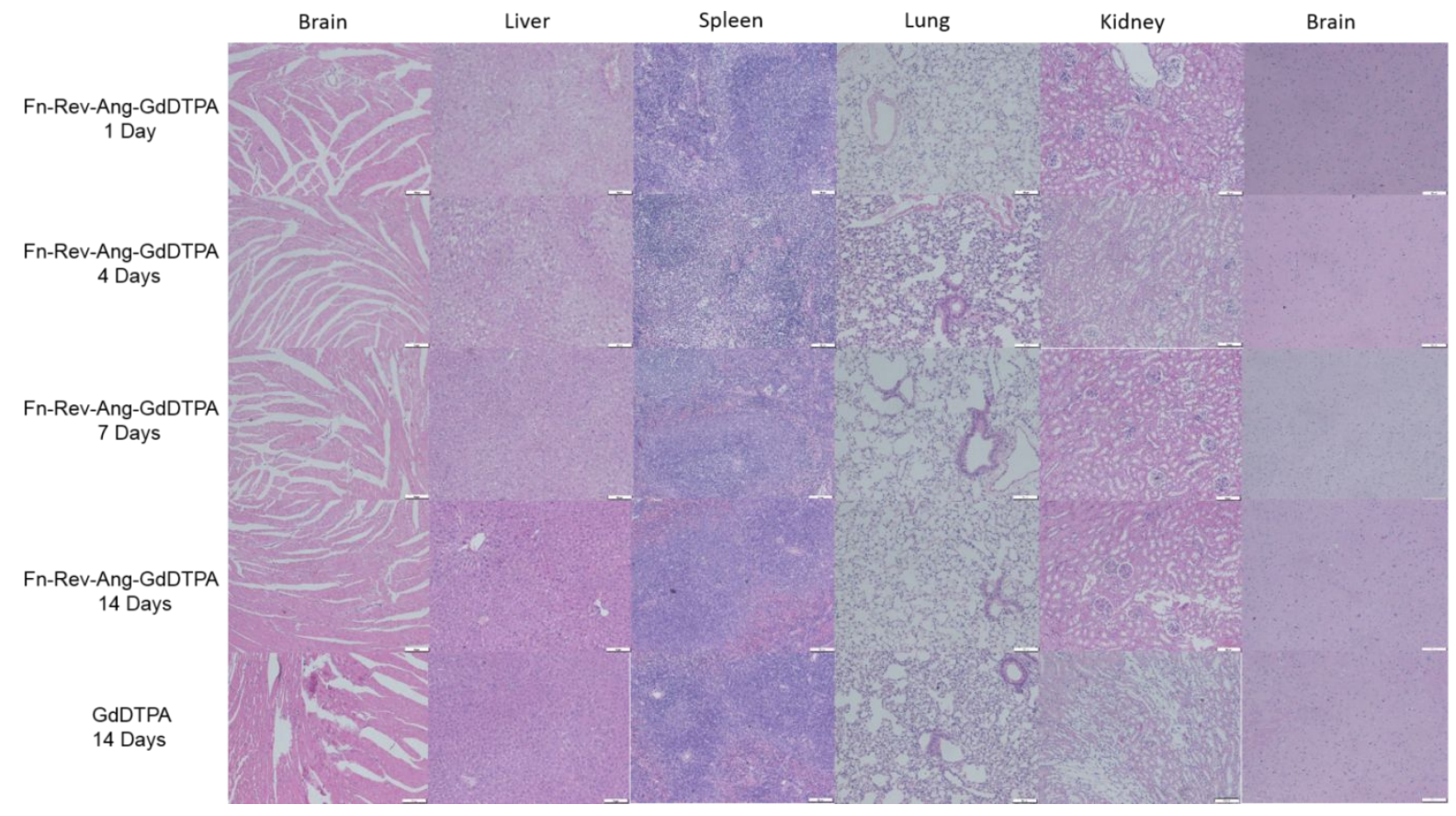

FigureS10 HE staining of organs (Brain, liver, spleen, lung, kidney ,brain )from Fn-Rev-Ang-GdDTPA-injecting mice in 1, 4, 7, 14 days and GdDTPA injecting mice in 14days. 
8.The results of magnetic resonance imaging(Figure S9A), bioluminescence imaging(Figure S9B), HE staining sections(Figure S9C) and transmission electron microscopy(Figure S9D, E, F) of brain tumor-bearing mice are shown in the Figure S10.
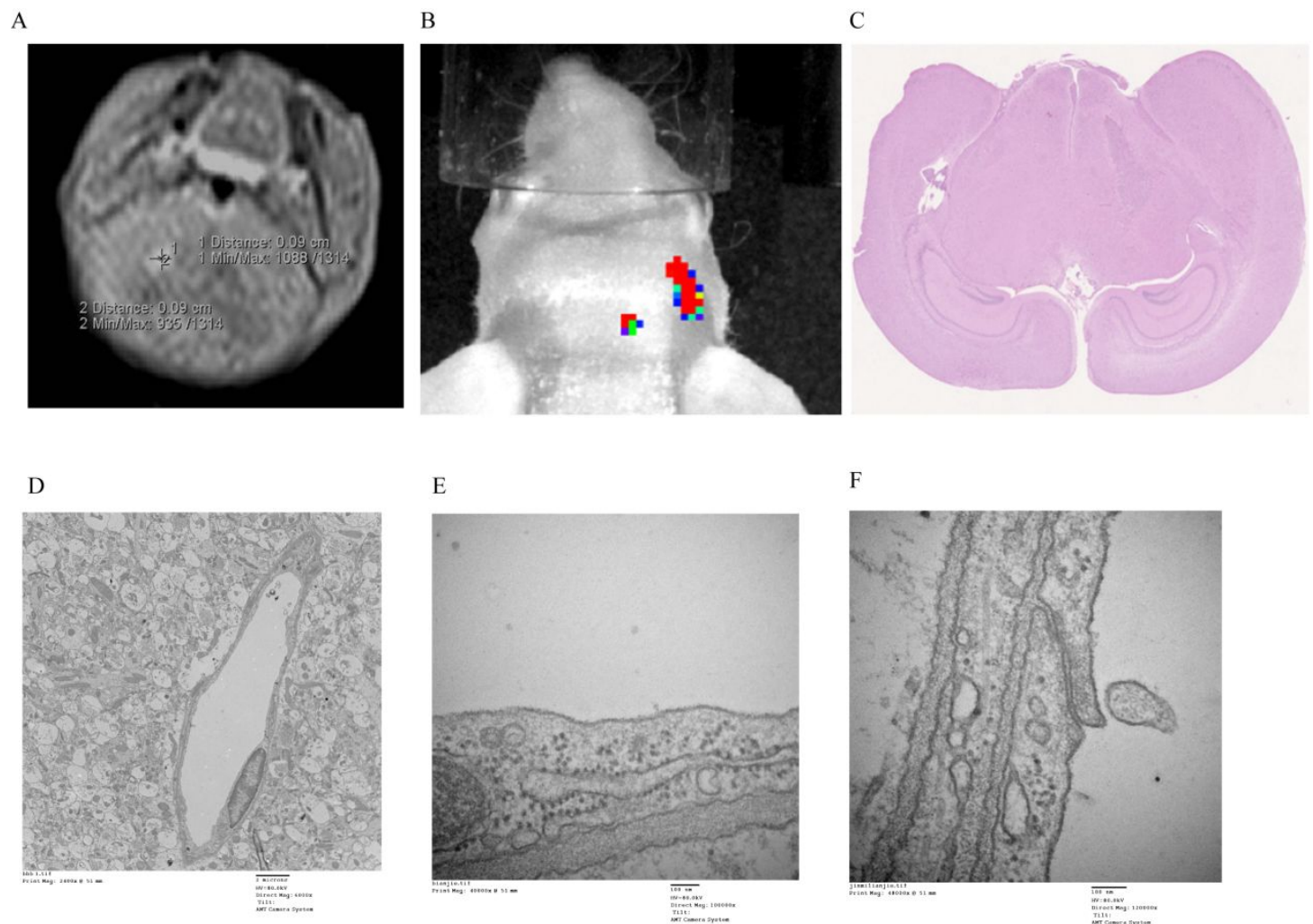

Figure S11 (A) MRI of tumor-bearing mice after Fn-Rev-Ang-GdDTPA injection(B).Bioluminescence imaging of tumor-bearing mice.(C) HE staining sections of tumor-bearing mice. (D) TEM show that the tumor-bearing mice capillaries of the brain are intact. (E) The basement membrane of tumor-bearing mice was intact. (F) The tight junction of tumor-bearing mice was intact. 
9.Stability test of nanoparticles
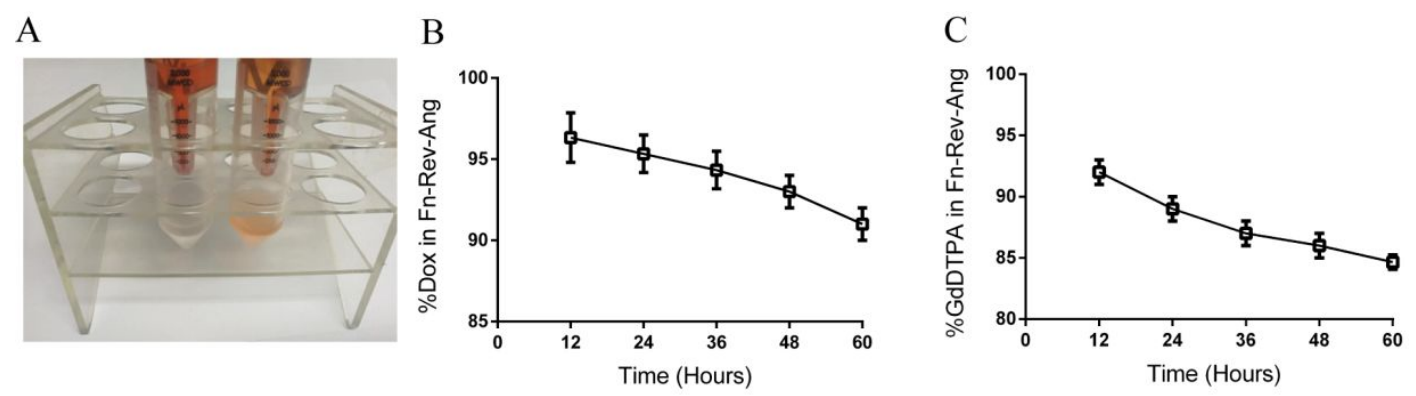

Figure S12 (A) the protein particles are relatively stable after being loaded with small molecules.After high speed centrifugation (using an ultrafiltration tube with a trapped volume of $3000 \mathrm{Da}$ ), the free small molecule filtrate on the right side is red, while the colorless filtrate on the left side is colorless. (B) Quantitative analysis, the loading amount of doxorubicin was more than $90 \%$ in 60 hours, and the filtrate almost did not contain DOX. (C) Quantitative analysis by ICP-MS, the loading amount of GdDTPA was more than $85 \%$ in 60 hours. 
10.Morphology of nanoparticles after drug loading. 
A

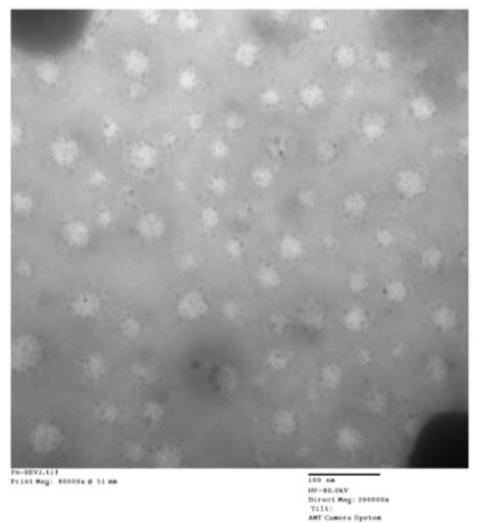

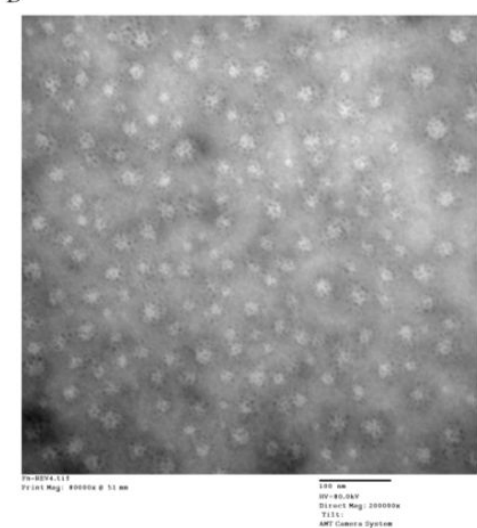

C

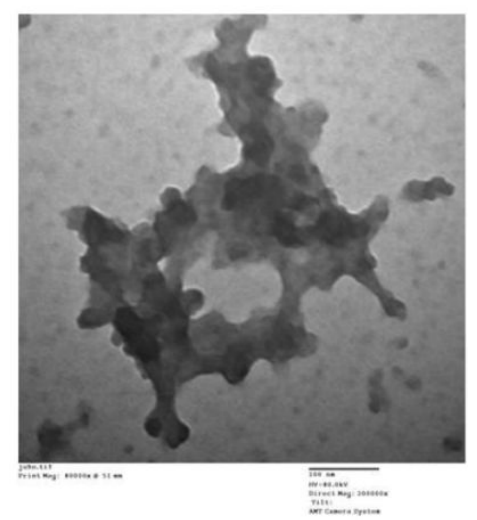

Figure S13 (A) TEM image of Fn-Rev-Ang-Dox, scale bar $=100 \mathrm{~nm}$. (B) TEM image of Fn-Rev-Ang-GdDTPA, scale bar $=100 \mathrm{~nm}$.(C)TEM image of Fn-Rev-Ang $(\mathrm{pH}=6)$ 